\title{
Using the health belief model to predict breast self examination among Saudi women
}

\author{
Mostafa A. Abolfotouh 1,2,3*, Ala'a A. BaniMustafa', Aisha A. Mahfouz, Mohammed H. Al-Assiri ${ }^{1}$,
} Amal F. Al-Juhani ${ }^{1}$ and Ahmed S. Alaskar ${ }^{1,2,3}$

\begin{abstract}
Background: In the Kingdom of Saudi Arabia, breast cancer (BC) usually presents at advanced stages and more frequently in young pre-menopausal women in comparison to western countries. There is controversy surrounding the efficacy of breast self examination (BSE) for early detection of BC in countries where other methods are available. This study aims to explore the perception towards breast cancer and towards BSE among Saudi women, using the Health Belief Model (HBM).
\end{abstract}

Methods: A convenient sample of adult Saudi female employees, working at King Abdulaziz Medical City, Riyadh, Saudi Arabia $(n=225)$, and their non-working adult female family members $(n=208)$, were subjected to the Arabic version of revised Champion's Health Belief Model Scale (CHBMS) and the Arabic version of Breast Cancer Awareness Measure (CAM), to assess their knowledge and attitude on BC respectively. Percentage mean score (PMS) for each HBM domain was calculated. Significant predictors of BSE practice were identified using logistic regression analysis and significance was considered at $p<0.05$.

Results: The majority of women heard about BSE (91.2\%), only $41.6 \%$ reported ever practicing BSE and $21 \%$ performed it regularly. Reported reasons for not doing BSE were: not knowing how to examine their breast (54.9\%), or untrusting themselves able to do it (24.5\%). Women were less knowledgeable about BC in general, its risk factors, warning signs, nature and screening measures (PMS:54.2 \%, 44.5 \%, 61.4\%, 53.2 \%, $57.6 \%$ respectively). They reported low scores of; perceived susceptibility, seriousness, confidence and barriers (PMS: $44.8 \%, 55.6 \%, 56.5 \%$ \& $41.7 \%$ respectively), and high scores of perceived benefits and motivation (PMS: $73 \%$ \& $73.2 \%$ respectively) to perform BSE. Significant predictors of BSE performance were: levels of perceived barriers $(p=0.046)$ and perceived confidence $(p=0.001)$ to BSE, overall knowledge on BC $(p<0.001)$, work status $(p=0.032)$ and family history of $\mathrm{BC}(p=0.011)$.

Conclusions: Saudi women had poor knowledge on BC, reported negative attitude towards BSE and their practice was poor. Working women and those with family history of $B C$, higher perceived confidence and lower perceived barriers on $\mathrm{HBM}$, and those with high level of knowledge on BC were more likely to perform BSE. Breast awareness as an alternative to BSE needs further investigations. HBM was shown as a valid tool to predict BSE practice among Saudi women.

Keywords: Breast cancer, HBM, Saudi women, Breast self examination, Screening, Breast awareness

\footnotetext{
* Correspondence: mabolfotouh@gmail.com

${ }^{1}$ King Abdullah International Medical Research Center (KAIMRC), Mail Code

1515, Riyadh, Saudi Arabia

${ }^{2}$ King Saud bin-Abdulaziz University for Health Sciences (KSAU-HS), Riyadh,

Saudi Arabia

Full list of author information is available at the end of the article
}

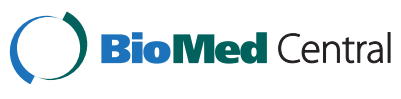

(c) 2015 Abolfotouh et al. Open Access This article is distributed under the terms of the Creative Commons Attribution 4.0 International License (http://creativecommons.org/licenses/by/4.0/), which permits unrestricted use, distribution, and reproduction in any medium, provided you give appropriate credit to the original author(s) and the source, provide a link to the Creative Commons license, and indicate if changes were made. The Creative Commons Public Domain Dedication waiver (http://creativecommons.org/publicdomain/zero/1.0/) applies to the data made available in this article, unless otherwise stated. 


\section{Background}

Breast cancer is the most frequent malignancy of women worldwide. It is the leading cause of female cancer related disability and mortality. in Saudi Arabia, breast cancer is the most common type of cancers among Saudi females and accounted for more than $25 \%$ of all newly diagnosed cancer among them [1], with the proportion of young age-onset much higher than in western countries $[2,3]$. It is usually present at advanced stages [4]. Many women miss early detection and treatment opportunities owing to lack of information, knowledge and awareness of breast cancer as well as to cancer screening practices [5].

A significant number of women present with advanced stages of the disease due to lack of information, knowledge and awareness of early detection measures. Previous studies showed limited knowledge about breast cancer screening, and few women performed screening for early detection purposes [6-8]. A recent study reported very low rates of breast cancer screening in Saudi Arabia, a country with free health services, and educational campaigns were recommended to improve $\mathrm{BC}$ screening and to address the barriers for BC screening [9].

Breast self-exam (BSE), mammography and clinical breast examination (CBE) are considered as screening methods for early detection of breast cancer. There is controversy surrounding the efficacy of BSE in countries where mammography and clinical breast exams are readily available. Data from two large trials in China and Russia [10-12] did not suggest a beneficial effect of screening by BSE, but reported increased harm in terms of increased number of benign lesions identified and an increased number of biopsies performed. However, in 2009, the U.S. Preventive Services Task Force concluded that there is insufficient evidence to recommend for or against teaching or performing routine breast self-examination [13]. The American Cancer Society now recommends the pros and cons of BSE be reviewed with women beginning in their 20 s and that the ultimate decision of whether to practice BSE be left up to the individual [14].

In the absence of evidence that routine, systematic $\mathrm{BSE}$ reduces deaths from $\mathrm{BC}$, a number of international organizations recommended that women look and feel for breast changes as part of general body awareness, while dressing or showering, so as to be aware of any changes from what is normal for them. This concept is known as "breast awareness (BA)" [15]. It is possible that increased breast awareness may have contributed in the decrease in mortality from breast cancer in some countries, although uncertainty exists whether the benefits of BA outweigh the harms [16].

Most women in previous studies held pessimistic views about the curability of breast cancer (58.2 \%) [17]. The Health Belief Model (HBM) has been used in several studies as a theoretical framework to study BSE and other breast cancer detection behaviors [18]. The HBM has been translated, tested and used for women of different cultures. The model stipulates that health-related behavior is influenced by a person's perception of the threat posed by a health problem and by the value associated with his/ her action to reduce that threat [19]. According to the HBM scale, a woman who perceives that she is susceptible to breast cancer and that breast cancer is a serious disease would be more likely to perform regular breast examinations. Similarly, a woman who perceives more benefits of and fewer barriers to BSE would be more likely to practice BSE [20]. In previous studies, BSE screening was linked to perception of risk [21, 22], perceived benefits [18, 22, 23], barriers [18, 22-24], confidence [18, 21, 23, 24], having heard/read about BC [24], motivation 18], susceptibility [18, 23], Knowledge of BSE issues [21, 23], employment [21], demographic characteristics [23] and regular visits to a physician $[23,24]$.

In Saudi Arabia, although some studies were conducted on BSE $[17,25,26]$, yet none of these studies investigated women's perception using the HBM. This study was designed to study the perception towards breast cancer and BSE among a group of Saudi women, using the HBM, through the following: 1) assessment of women's beliefs and attitudes surrounding breast cancer and breast self examination using the health belief model, 2) determination of the level of knowledge among Saudi women regarding breast cancer and breast cancer-related practices, 3) determination of breast cancer-related behaviors, and 4) identification of factors influencing the practice of BSE. The results of this study may provide a baseline assessment for future intervention programs to promote early detection and early management of $\mathrm{BC}$.

\section{Methods}

\section{Study area/setting}

Study was conducted in outpatient clinic at King Abdulaziz Medical City (KAMC), Riyadh , Saudi Arabia. KAMC commenced its operations in may 1983. Since then it has continued expanding while providing service for a rapidly growing patient population in all of its catchments areas. At KAMC, the bed capacity increased to 1000 beds in addition to 25 beds allocated for expected surgical operations in Ward 19, and 132 beds for admission of emergency cases. The healthcare quality on an international scope, NGHA has passed the requirements for accreditation under the Joint Commission International (JCI) standards with excellent performance in December, 2006.

\section{Study subjects}

Saudi female employees above 18 years old, working at King Abdulaziz Medical City, (KAMC), Riyadh, Saudi 
Arabia, and their non-working adult female family members. , who were willing to participate, made the target of the study..In Saudi culture, paternalistic approach is practiced when dealing with females, that would not allow an easy access to non-working females to participate in the study. Thus, each working woman was asked to invite her non-working adult female family member(s) to participate in the study by filling the questionnaire. Thus, work status as a possible predictor of women's perception and practice on BSE, was investigated. Doctors and nurses were excluded so as to allow for the study be representative of Saudi women in general.

\section{Study design}

A cross sectional study was applied using self-adminestered questionnaire.

\section{Sample size and sampling technique}

Based on the assumption of $58.2 \%$ of women holding pessimistic views about the curability of breast cancer in a previous study [17], and with a $5 \%$ margin of error and $95 \% \mathrm{CI}$, the estimated sample size was 374 women. This sample was allocated equally from the working and nonworking females. Working women were selected by convenient sampling from adult female employees at KAMC, Riyadh, Saudi Arabia during the time of study $(n=225)$, Each female employee who showed interest to participate in the study was asked to take a questionnaire home to be filled by one non-working adult female family member, and to return the filled questionnaire the day after. Thus, a total of 433 females (225 employees \& 208 non-working females) participated in the study.

\section{Data collection}

The questionnaire was initially designed based on previously validated questionnaires $[4,17,27-29]$. It is originally designed in English and then translated into Arabic language and was validated in a pilot study before finally utilized. The questionnaire is composed of five sections:

(1) Section one was to collect data on demographical characteristics of participants;

(2)Section two was about knowledge of participants about breast self-examination;

(3) Section three was about level of practice of breast self-examination;

(4) Section four was the use of Breast Cancer Awareness Measure (Breast CAM) version 2 [30] to collect data from Saudi females about knowledge of participants regarding screening tests, nature of breast cancer, warning signs of breast cancer and risk factors. To assess reliability of the tool, test-retest reliability was done on a pilot sample of 20 women (10 working \& 10 non-working) and Cronbach's alpha was 0.82; and
(5) Section five was the use of the health belief model (HBM) to collect data about women's perception to BSE. The Arabic version of revised Champion's Health Belief Model Scale (CHBMS) [31] was tested for validity and reliability in Mikhail and Petro-Nustas [20] and found satisfactory. It consists of 6 concepts: perceived susceptibility to illness ( 5 items), perceived seriousness of illness ( 7 items), perceived benefits for the presumed action ( 6 items), perceived barriers for the presumed action (7 items), confidence in one's ability (11 items) and health motivation (7 items) [32]. All the items have 5 response choices ranging from strong disagreement (1 point) to strong agreement (5 points). All scales are positively related to screening behavior, except for barriers which are negatively associated. Reported Cronbach's alpha for the CHBMS ranged from 0.69 to 0.83 . The reliability of these subscales for this study ranged from 0.78 to 0.89 . The CHBMS was used after securing written permission from the author. The tool was pilot tested, few revisions were made and then administered as a self administrative questionnaire.

\section{Ethical considerations}

Participation in the study was voluntary, and each participant was able to withdraw from the study at any time. The investigators explained the aim of the study to the participants. Agreement to fill the questionnaire was considered as a consent to participate in the study. The study protocol received ethical approval from the IRB of the Saudi National Guard Health Affairs, Riyadh, Saudi Arabia, (application number SP14/107).

\section{Data management}

Data entry and statistical analysis were performed using SPSS $^{\circ}$ version 20.0 (IBM Corporation, Armonk, NY, USA). Descriptive statistics, such as percentages, frequencies, means, and standard deviations, were used to measure the demographic variables and the responses to knowledge and attitude statements. Analytical statistics were applied to investigate the association of knowledge and attitude with demographic variables. Logistic regression analysis was performed to identify the significant predictors for BSE practice. Statistical significance was set at $p<0.05$ for all analyses.

\section{Results}

Table 1 shows the distribution of 433 women according to some socio-demographic characteristics. The majority of women were of age 18 to less than 35 years (62.1\%), with an average age of $39.4 \pm 7.2$ years. The majority were secondary or more educated ( $95.6 \%$ ), one-half were employees (52\%), and one-half from higher income families of more than 10,000 Saudi Riyals (53.8 \%). 
Table 1 Women's Sociodemographic characteristics

\begin{tabular}{|c|c|c|}
\hline Demographic characteristics & no $(N=433)$ & $\%$ \\
\hline \multicolumn{3}{|l|}{ Age in years: } \\
\hline $18-<35$ & 294 & 68.1 \\
\hline $35-45$ & 86 & 19.9 \\
\hline$<45$ & 52 & 12.0 \\
\hline$($ Mean \pm SD) & $39.4 \pm 7.2$ & \\
\hline \multicolumn{3}{|l|}{ Education level: } \\
\hline$<$ Secondary & 19 & 04.4 \\
\hline$\geq$ Secondary & 414 & 95.6 \\
\hline \multicolumn{3}{|l|}{ Marital status: } \\
\hline Single & 206 & 47.6 \\
\hline Married & 196 & 45.2 \\
\hline Widow/Divorced & 31 & 07.2 \\
\hline \multicolumn{3}{|l|}{ Work status: } \\
\hline Employee & 225 & 52.0 \\
\hline Non-employee & 208 & 48.0 \\
\hline \multicolumn{3}{|l|}{ Monthly income: } \\
\hline$<5000$ SR & 62 & 14.3 \\
\hline $5000-10000 S R$ & 138 & 31.9 \\
\hline$>10000 \mathrm{SR}$ & 233 & 53.8 \\
\hline \multicolumn{3}{|l|}{ Family history of $B C$ : } \\
\hline No & 334 & 77.1 \\
\hline Near relatives (Mother/Sister/Daughter) & 14 & 03.3 \\
\hline Far relatives & 85 & 19.6 \\
\hline
\end{tabular}

Family history of BC was reported by $22.9 \%$ of women (3.3\% near relatives \& $19.6 \%$ far relatives).

Table 2 shows the distribution of women according to knowledge and practice of BC and BSE issues. Almost all women (91.2 \%) in the present study heard about BSE, mostly from educational public campaigns (54.7\%), TV (40.5 \%) and internet (38.2 \%). With regard to knowledge of BSE, about three-quarters of all women (74.7 \%) reported the of $\geq 19$ years as the age of initiation of BSE, and only $43.5 \%$ reported that it should be done monthly, and $44.8 \%$ reported that it should be done five days after menses, respectively.

With regard to practice of BSE, less than one-half $(41.6 \%)$ of women reported that they have practiced BSE for 1 to 12 times with an average of $4.1 \pm 6.3$ times per year. The average age of initiation of BSE was $26.8 \pm$ 7.7 years. Only $21.1 \%$ reported performing it in less than a month, $45.6 \%$ in less than a year, while $33.3 \%$ reported not doing it for more than a year. Home was the main place for the majority of women where to do BSE (74.0\%), followed by hospitals (30.4\%).

Reasons for doing BSE as reported by 180 women were: to examine their breast regularly $(62.8 \%)$, and to
Table 2 Women's Knowledge and reported practices on BSE

\begin{tabular}{lrl}
\hline (A) Knowledge about BSE & no $(N=433)$ & $\%$ \\
\hline Have you heard about BSE & 395 & \\
Yes & 38 & 01.2 \\
No & & \\
Age of SBE starting $(n=395)$ & 17 & 04.3 \\
$<19$ & 295 & 74.7 \\
$\geq 19$ & 83 & 21.0 \\
Don't know & &
\end{tabular}

How often could BSE be done per year $(n=395)$

Daily

Weekly

$\begin{array}{rr}1 & 0.3 \\ 3 & 0.8 \\ 172 & 43.5 \\ 150 & 37.9 \\ 69 & 17.5\end{array}$

Don't know

17.5

When BSE should be performed with regular menses $(n=395)$

$\begin{array}{lrl}\text { Regular day of each month } & 31 & 07.9 \\ 5 \text { days after } & 177 & 44.8 \\ \text { Do not know } & 187 & 47.3 \\ \text { Source of information }(n=395)^{a} & & \\ \text { TV } & 160 & 40.5 \\ \text { Radio } & 16 & 04.1 \\ \text { Educational camping Public } & 216 & 54.7 \\ \text { Internet } & 151 & 38.2 \\ \text { Medical journal } & 70 & 17.7 \\ \text { Primary health care } & 50 & 12.7 \\ \text { Friends } & 39 & 09.9 \\ \text { Other } & 37 & 09.4\end{array}$

(B) BSE Practices

no $(N=433) \quad \%$

Have you done BSE before $(n=433)$

Yes

$180 \quad 41.6$

No

$253 \quad 58.4$

Number per year (Mean \pm SD)

$4.1 \pm 6.3$

Where do you perform BSE $(n=181)^{a}$

Home

$134 \quad 74.0$

Early detection programs

$7 \quad 03.9$

Private hospital

$22 \quad 12.2$

Governmental hospital

$33 \quad 18.2$

The last time performed BSE $(n=180)$

Less than 1 month

$38 \quad 21.1$

Less than 1 year

$82 \quad 45.6$

More than 1 year

$60 \quad 33.3$

${ }^{a}$ Non mutually exclusive 
check for the progression of some abnormal changes (26.7\%), or because of doctors' advice (19.3\%). Reasons for not doing BSE as reported by 235 women were: because of not knowing how to examine their breast $(54.9 \%)$, or because of untrusting themselves able to do it (24.5\%), Fig. 1 .

\section{Knowledge about BC}

The overall percentage mean score (PMS) of knowledge is $(54.2 \%)$, denoting low level of knowledge. This PMS was the lowest for the knowledge of risk factors $(44.5 \%)$, and the highest for the knowledge of warning signs (61.4\%), Fig. 2.

With regard to knowledge of screening measures, about one-half of women reported knowing how to perform BSE, and less than a half reported knowing mammography (41.1\%), and clinical breast examination (44.2\%), with an overall PMS of $57.6 \%$. Regarding the knowledge of breast cancer (BC), the majority of women (88.2\%) reported that $\mathrm{BC}$ is curable in its early stages, and less than two-thirds (60.5\%) considered it as fatal if not treated, common in women over 50 (61.4\%), and that nipple discharge is important $(60.3 \%)$. Only $22.6 \%$ and $18.1 \%$ reported that it is common in obese, and can be in both breasts, respectively, Table 3.

The majority of women reported the breast lump $(74.8 \%)$ and the abnormal changes in breast size (73.7 \%) as warning signs, and two-thirds reported discharge from the nipple $(76.4 \%)$ or change in its shape (67.6\%). Early menarche as a warning sign was reported by only $23.6 \%$ of all women, Table 3 .

As for knowledge of risk factors of $\mathrm{BC}$, low proportions of women reported correctly the different risk factors, that varied from $15 \%$ for late menopause, $28 \%$ for obesity, $31.3 \%$ for hormone replacement therapy (HRT), $36.5 \%$ for oral contraceptive pills (OCP), $44.6 \%$ for increased age to $50.8 \%$ and $53.6 \%$ for alcohol and smoking respectively. However, the majority of women reported that neither breast feeding practice $(73.4 \%)$ nor physical exercising (67.8 \%) is a risk factor, while only $21.9 \%$ of women reported that trauma to the breast is not a risk factor for $\mathrm{BC}$, Table 3.

\section{Perception towards BSE}

Figure 2 shows the PMS of different domains of attitude to $\mathrm{BC}$ and BSE as measured by the health belief model (HBM). The overall PMS of seriousness domain is low (55.6\%.), with less likelihood to practice BSE. However, the majority of women disagreed/strongly disagreed that $\mathrm{BC}$ is hopeless disease $(78.5 \%)$ and that they would not live more than 5 years with BC $(66.2 \%)$. Also, the overall PMS for susceptibility domain is low (44.8\%), with less likelihood to practice BSE. Only less than $10 \%$ of all women who agreed/strongly agreed they; are susceptible to $\mathrm{BC}$ in the future $(6.7 \%)$, feel susceptible to $\mathrm{BC}$ (7.6\%), feel susceptible than anyone $(4.8 \%)$, feel the chance of getting $\mathrm{BC}$ as big (4.1\%), or feel highly susceptible to $\mathrm{BC}$ in the next 10 years (3.5\%), Table $4 .$.

The overall PMS of confidence domain is low (56.5\%), reflecting less likelihood to practice BSE. About one-third of all women agreed/strongly agreed that they know how to perform BSE (35.6\%), and that are confident in performing BSE correctly (30.7\%), they are sure of the steps of BSE (25.7\%), and can use the correct parts of their fingers when performing BSE (29.1\%). However, only $18.7 \%$ reported being confident to discover breast tumors by performing BSE. The ability to discover breast tumor at different sizes was agreed/strongly agreed by $45.0 \%$,

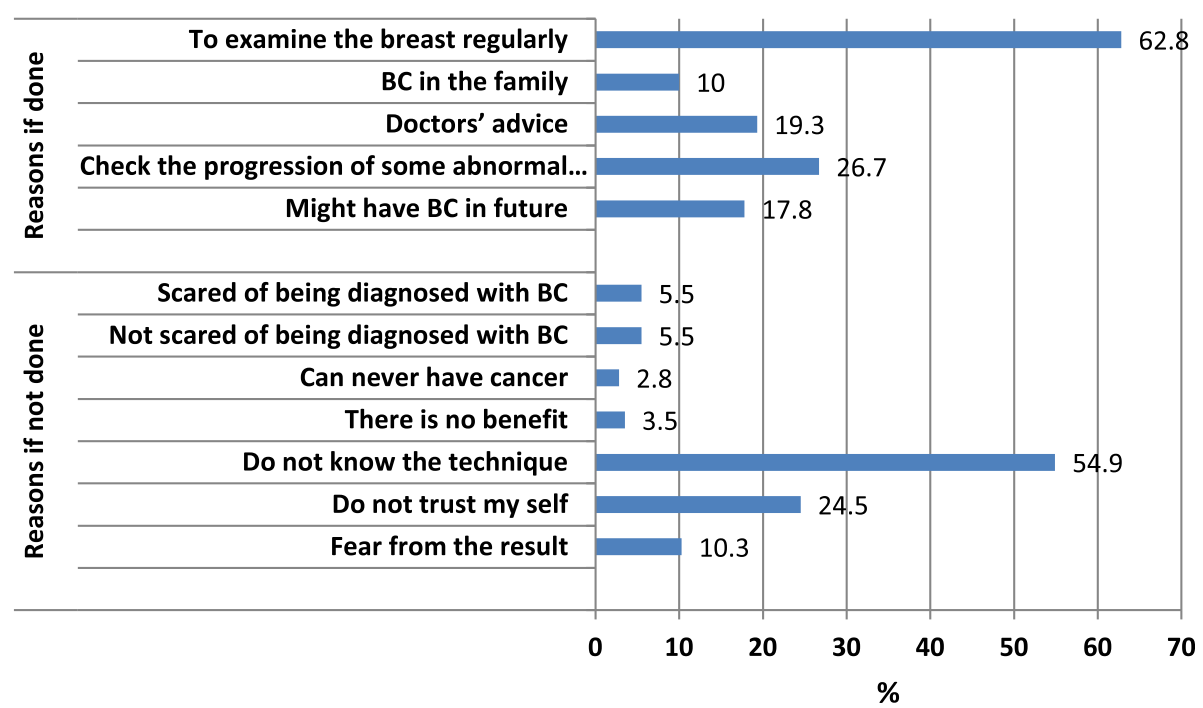

Fig. 1 Reasons of doing and not doing BSE as reported by women 


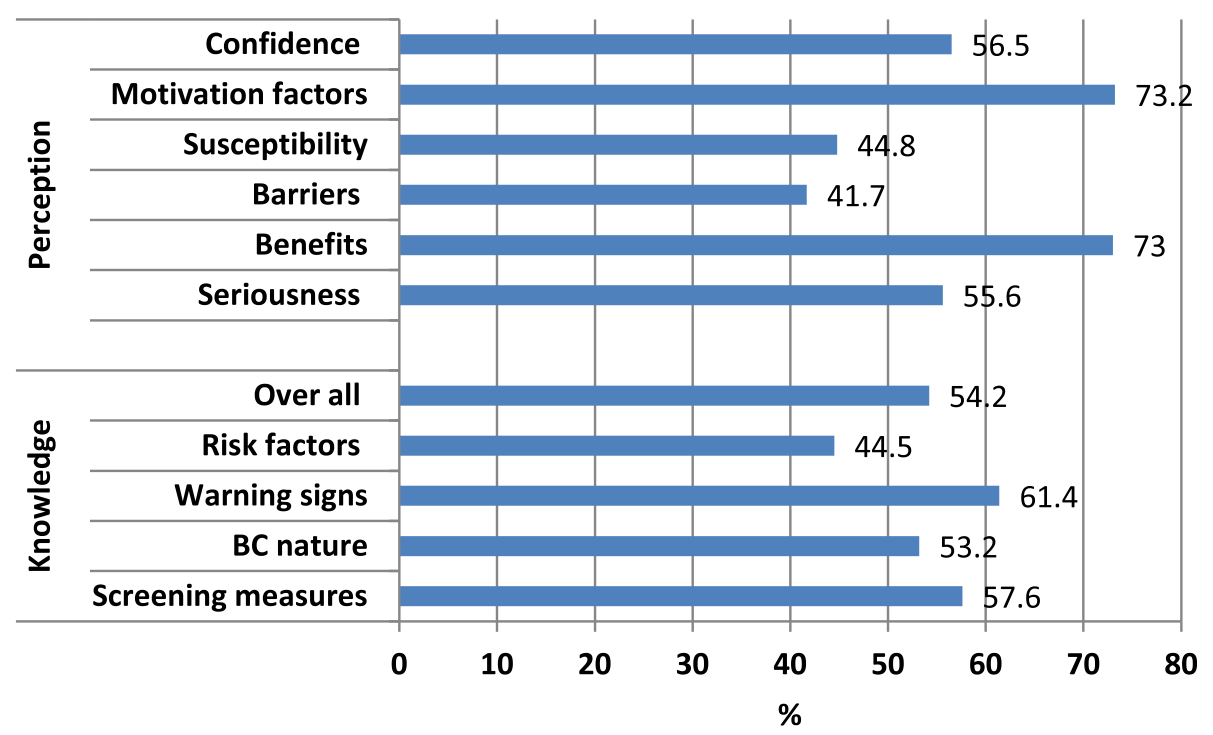

Fig. 2 Percentage mean score of knowledge and attitude scales

$18.4 \%$ and $10.0 \%$ of women, for 3 sizes of lumps respectively, Table 4.

On the other hand, the overall PMS of benefit domain is reasonable $(73.0 \%)$, with more likelihood to practice BSE. However, the majority of women agreed/ strongly agreed that performing BSE monthly would help in; early detection of BC (78.5\%), detection of tumors before going to doctors $(69.1 \%)$, decreasing complications and chance of operation (64.1\% \& $54.0 \%$, respectively), if they got BC. The overall PMS of barrier domain is low (41.7\%), with more likelihood to practice BSE. The majority of women disagreed/strongly disagreed that performing BSE; is a trivial thing (85.6\%), has no private place to do (80.7\%), would not change the fact that getting $\mathrm{BC}$ is a destiny (77.6\%), would make shame and embarrassment (71.6\%), or is unfavorable thing (63.7\%), Table 4.

The overall PMS of motivation factors domain is reasonable (73.2 \%), reflecting more likelihood to practice BSE. The majority of women agreed/strongly agreed that; keeping their good health is important to them (95.3\%), they wish to discover health problems early (94.4\%), they always seek new information, and feel the importance of activities, that improve their health (84.3 \%78.6 \% respectively). However, small proportion of women agreed/strongly agreed that; their diet contains complete and balanced diet (42.5\%), they practice exercise at least 3 times weekly (37.0\%), or they perform periodic medical checkup (36.7\%), Table 4.

Figure 3. shows that the PMS of overall knowledge of $\mathrm{BC}$ issues was significantly higher among women who practiced BSE than among those who have not (66.7 \% versus $45.5 \%, \mathrm{t}=11.78, p<0.001)$. Women who practiced BSE showed significantly higher in all domains of knowledge: knowledge of screening measures (80.2\% versus $41.6 \%, \mathrm{t}=16.59, p<0.001)$, of $\mathrm{BC}$ nature $(62.0 \%$ versus $46.2 \%, \mathrm{t}=8.13, p<0.001)$, of warning signs ( $71.3 \%$ versus $54.4 \%, \mathrm{t}=6.15, p<0.001)$, and of risk factors $(51.3 \%$ versus $39.7 \%, \mathrm{t}=5.30, p<0.001)$.

Figure 3 shows that women who practiced BSE had significantly higher benefits ( $75.8 \%$ versus $71.1 \%, t=3.69$, $p<0.001)$ and motivation factors scores $(75.2 \%$ versus $71.7 \%, \mathrm{t}=3.15, p=0.002)$, and lower barrier scores (37.5 \% versus $44.6 \%, \mathrm{t}=5.82, p<0.001$ ). than those who did not. However, both groups of women were comparable in seriousness and susceptibility PMS.

Table 5 shows the logistic regression analysis of BSE practice among women, with some independent variables. After adjustment for all possible confounders, it was found that the significant predictors to practice BSE were: positive family history of $\mathrm{BC}(p=0.011)$, employment $(p=$ $0.032)$, higher PMS of overall knowledge of $\mathrm{BC}$ issues $(p<$ $0.001)$ higher PMS of confidence domain $(p=0.001)$ and lower PMS of barriers domain $(p=0.046)$.

\section{Discussion}

This study focused on defining the health beliefs of Saudi women regarding BSE and the influencing factors. The literature supports the argument that regular practice of BSE influences treatment, prognosis and survival rates [33, 34]. In the present study, almost all women heard about BSE. This figure was higher than other figures in the previous studies in Saudi Arabia such as; Jeddah (39.6 \%) [35], Qassim (12 \%) [36] and Riyadh (10.4\%) [37]. However, it was comparable with figures in other countries such as Sweden [38], Austria [39], Nigeria [40] and Egypt (10.4\%) [41]. 
Table 3 Women's responses to different statement on breast cancer issues

\begin{tabular}{|c|c|c|c|c|c|c|}
\hline \multirow[t]{2}{*}{ Knowledge domains } & \multicolumn{2}{|l|}{ Yes } & \multicolumn{2}{|l|}{ No } & \multicolumn{2}{|c|}{ Don't know } \\
\hline & no & $\%$ & no & $\%$ & no & $\%$ \\
\hline \multicolumn{7}{|l|}{ Screening } \\
\hline Do you know about mammogram & 178 & 41.1 & 230 & 53.1 & 25 & 05.8 \\
\hline Do you know how to perform BSE & 231 & 53.3 & 176 & 40.7 & 26 & 06.0 \\
\hline Do you know about clinical examination of breast & 191 & 44.2 & 205 & 47.5 & 36 & 08.3 \\
\hline $\begin{array}{l}\text { Is it possible for screening measures to enhance } \\
\text { the chance of recovery }\end{array}$ & 396 & 91.4 & 15 & 03.5 & 22 & 05.1 \\
\hline \multicolumn{7}{|l|}{ Breast Cancer } \\
\hline $\mathrm{BC}$ is curable in early stages & 382 & 88.2 & 5 & 01.2 & 46 & 10.6 \\
\hline $\mathrm{BC}$ is highly mortality without treatment & 262 & 60.5 & 45 & 10.4 & 126 & 29.1 \\
\hline Painless in early stages & 215 & 49.7 & 36 & 08.3 & 182 & 42.0 \\
\hline $\mathrm{BC}$ more common in women over 50 & 266 & 61.4 & 42 & 09.7 & 125 & 28.9 \\
\hline Occurs in one breast only & 164 & 38.2 & 75 & 17.5 & 190 & 44.3 \\
\hline $\mathrm{BC}$ more common in obese women & 98 & 22.6 & 98 & 22.6 & 237 & 54.8 \\
\hline \multicolumn{7}{|l|}{ Warning signs } \\
\hline Nipple discharge is important & 261 & 60.3 & 37 & 08.5 & 135 & 31.2 \\
\hline A lump is definitely cancer & 63 & 14.6 & 278 & 64.4 & 91 & 21.0 \\
\hline Breast lump & 324 & 74.8 & 32 & 07.4 & 77 & 17.8 \\
\hline Early menarche & 102 & 23.6 & 114 & 26.4 & 216 & 50.0 \\
\hline Sudden and abnormal changes in size & 319 & 73.7 & 21 & 04.8 & 93 & 21.5 \\
\hline Discharges from nipple & 292 & 67.4 & 31 & 07.2 & 110 & 25.4 \\
\hline Changes in nipple shape & 292 & 67.6 & 25 & 05.8 & 115 & 26.6 \\
\hline \multicolumn{7}{|l|}{ Risk Factors } \\
\hline Radiotherapy & 149 & 34.5 & 56 & 13.0 & 227 & 52.5 \\
\hline Hormonal replacement & 135 & 31.3 & 51 & 11.8 & 246 & 56.9 \\
\hline Obesity & 121 & 28.0 & 114 & 26.4 & 197 & 45.6 \\
\hline Practice physical exercise & 39 & 09.0 & 293 & 67.8 & 100 & 23.2 \\
\hline Smoking & 232 & 53.6 & 61 & 14.1 & 140 & 32.3 \\
\hline Alcohol & 220 & 50.8 & 54 & 12.5 & 159 & 36.7 \\
\hline Increase with age & 193 & 44.6 & 91 & 21.0 & 149 & 34.4 \\
\hline Low fat intake & 45 & 10.4 & 200 & 46.2 & 188 & 43.4 \\
\hline Late menopause & 69 & 15.9 & 116 & 26.8 & 248 & 57.3 \\
\hline Long oral contraceptive pills & 158 & 36.5 & 70 & 16.2 & 205 & 47.3 \\
\hline Family history of breast cancer & 307 & 71.2 & 39 & 9.1 & 85 & 19.7 \\
\hline Breast feeding practice & 20 & 04.6 & 318 & 73.5 & 95 & 21.9 \\
\hline Trauma to breast area & 149 & 34.4 & 95 & 21.9 & 189 & 43.7 \\
\hline
\end{tabular}

In our study, less than one-half (41.6\%) of women reported that they have practiced BSE for 1 to 12 times with an average of $4.1 \pm 6.3$ times per year. The average age of initiation of BSE was $26.8 \pm 7.7$ years. Only $21.1 \%$ reported performing it in less than a month, $45.6 \%$ in less than a year, while $33.3 \%$ reported not doing it for more than a year. This figure is comparable with that reported in studies conducted in Europe (44 \%) [42], Hong Kong (52 \%) [43], Italy (30 \%) [44], Nigeria (11 \%) [45] and Malaysia (19\%) [46], and is higher than figures reported in studies in Alexandria, Egypt (2.65 \%) [41], Tehran, Iran (6 \%) [47], Qassim, KSA (19 \%) [36] and Istanbul, Turkey (10.2\%) [48]. Home was the main place for the majority of women where to do BSE (74.0 \%), followed by hospitals (30.4\%). 
Table 4 Women's responses to the different attitude items of the HBM

\begin{tabular}{|c|c|c|c|c|c|c|}
\hline \multirow[t]{2}{*}{ Attitude } & \multicolumn{2}{|c|}{ Disagree/ Strongly disagree } & \multicolumn{2}{|c|}{ Neutral } & \multicolumn{2}{|c|}{ Agree/ Strongly agree } \\
\hline & no & $\%$ & no & $\%$ & no & $\%$ \\
\hline \multicolumn{7}{|l|}{ Seriousness } \\
\hline BC is a hopeless disease & 340 & 78.5 & 71 & 16.4 & 22 & 5.1 \\
\hline I think I will not live more than 5 ys. with BC & 286 & 66.2 & 108 & 25 & 38 & 8.8 \\
\hline When I think about BC my heart beat faster & 228 & 52.7 & 77 & 17.8 & 128 & 29.5 \\
\hline I am afraid even to think about BC & 215 & 49.7 & 55 & 12.7 & 163 & 37.6 \\
\hline If I got BC this will threaten my marital life & 166 & 38.3 & 138 & 31.9 & 128 & 29.8 \\
\hline All my life will be changed if I got BC & 160 & 37.0 & 124 & 28.7 & 148 & 34.3 \\
\hline I think the problem about BC will persist long & 98 & 22.6 & 152 & 35.1 & 183 & 42.3 \\
\hline The thought of BC scare me & 81 & 18.7 & 47 & 10.9 & 305 & 70.4 \\
\hline \multicolumn{7}{|l|}{ Susceptibility } \\
\hline I am susceptible to breast cancer in the future & 188 & 43.4 & 216 & 49.9 & 29 & 6.7 \\
\hline I feel that I am susceptible to breast cancer & 242 & 55.9 & 158 & 36.5 & 33 & 7.6 \\
\hline I think I am susceptible to breast cancer more than anyone & 280 & 64.7 & 132 & 30.5 & 21 & 4.8 \\
\hline My personal chance of getting breast cancer is big & 253 & 58.6 & 161 & 37.3 & 18 & 4.1 \\
\hline I am highly susceptible to breast cancer next 10 years & 231 & 53.3 & 187 & 43.2 & 15 & 3.5 \\
\hline \multicolumn{7}{|l|}{ Confidence } \\
\hline I know how to perform BSE & 134 & 30.9 & 145 & 33.5 & 154 & 35.6 \\
\hline I am confident in performing BSE correctly & 117 & 27.0 & 183 & 42.3 & 133 & 30.7 \\
\hline I am sure of the steps of BSE & 152 & 35.1 & 170 & 39.3 & 111 & 25.6 \\
\hline I can use the correct parts of my fingers when performing BSE & 139 & 32.1 & 168 & 28.8 & 126 & 29.1 \\
\hline I am confident I can discover breast tumors by performing BSE & 152 & 35.1 & 200 & 46.2 & 81 & 18.7 \\
\hline I can discover breast tumor at size of big spot & 90 & 20.8 & 148 & 34.2 & 195 & 45.0 \\
\hline I can discover breast tumor at size of small peas & 172 & 39.8 & 181 & 41.8 & 80 & 18.4 \\
\hline I am able to discover breast tumors alone through performing BSE & 178 & 41.1 & 193 & 44.6 & 62 & 14.3 \\
\hline I can discover breast tumor at size of small spot & 188 & 43.4 & 197 & 45.5 & 48 & 11.1 \\
\hline I am able to differentiate between normal and abnormal breast tissue through BSE & 196 & 45.3 & 171 & 39.5 & 66 & 15.2 \\
\hline When I look at mirror I can identify abnormal changes in my breast & 127 & 29.4 & 130 & 30.0 & 176 & 40.6 \\
\hline \multicolumn{7}{|l|}{ Benefits } \\
\hline Performing BSE monthly help in early detection of BC & 26 & 6.0 & 67 & 15.5 & 340 & 78.5 \\
\hline Performing BSE monthly help in detection of tumors before going to doctors & 40 & 9.2 & 94 & 21.7 & 299 & 69.1 \\
\hline Performing BSE monthly will decrease complications of BC if I got it & 38 & 8.8 & 117 & 27.1 & 277 & 64.1 \\
\hline Performing BSE decrease the chance of making operation if I got it & 52 & 12.0 & 147 & 33.0 & 234 & 54.0 \\
\hline When I performed BSE I became self-satisfied & 57 & 13.2 & 155 & 35.9 & 220 & 50.9 \\
\hline Performing BSE decrease the anxiety about BC & 44 & 10.2 & 116 & 26.8 & 273 & 63.0 \\
\hline \multicolumn{7}{|l|}{ Barriers } \\
\hline Performing BSE is a trivial thing & 370 & 85.6 & 42 & 09.7 & 20 & 4.7 \\
\hline Performing BSE is unfavorable thing & 276 & 63.7 & 94 & 21.7 & 63 & 14.6 \\
\hline No private place at home to perform BSE & 349 & 80.7 & 57 & 13.2 & 26 & 6.1 \\
\hline Feeling of shame and embarrassment when performing BSE & 310 & 71.6 & 70 & 16.2 & 59 & 12.2 \\
\hline Performing BSE takes long time & 239 & 55.2 & 162 & 37.4 & 32 & 7.4 \\
\hline Performing BSE increase my anxiety about liability of having $B C$ & 244 & 56.3 & 95 & 22.0 & 94 & 21.7 \\
\hline I think getting breast cancer is a destiny and BSE will not change it & 336 & 77.6 & 68 & 15.7 & 29 & 6.7 \\
\hline
\end{tabular}

Motivation factors 
Table 4 Women's responses to the different attitude items of the HBM (Continued)

\begin{tabular}{|c|c|c|c|c|c|c|}
\hline Keeping my good health is important to me & 5 & 1.2 & 15 & 03.5 & 413 & 95.3 \\
\hline I wish to discover health problems that occur early & 9 & 2.1 & 15 & 03.5 & 409 & 94.4 \\
\hline I always seek new information that improve my health & 19 & 4.4 & 49 & 11.3 & 365 & 84.3 \\
\hline I feel the importance of activities that improve my health & 44 & 10.1 & 49 & 11.3 & 340 & 78.6 \\
\hline My diet contains complete and balanced meals & 116 & 26.8 & 133 & 30.7 & 184 & 42.5 \\
\hline I practice exercise at least 3 times weekly & 180 & 41.5 & 93 & 21.5 & 106 & 37.0 \\
\hline I perform periodic medical checkup & 204 & 47.1 & 70 & 16.2 & 159 & 36.7 \\
\hline
\end{tabular}

In the literature, the main reasons for not-practicing BSE among those who claimed not to practice BSE included being not informed about how to practice it [49], fear or anxiety to discover the presence of a serious disease $[27,50]$, or not fully convinced regarding the importance of BSE $[27,50]$. In the present study, reasons for not doing BSE as reported by 235 women were: because of not knowing how to examine their breast, or because of untrusting themselves able to do it. This finding justify why confidence in performing BSE in the HBM was a significant predictor of BSE practice. Being breast aware should be emphasized more than being BSE technique -abled [16].

According to the HBM, a woman who perceives that she is susceptible to breast cancer and that breast cancer is a serious disease would be more likely to perform regular breast examinations. Similarly, a woman who perceives more benefits of and fewer barriers to BSE would be more likely to practice BSE [20]. In the present study, women reported lower scores of susceptibility, seriousness and confidence that are in favour of not performing BSE. However, the higher benefits, motivation and confidence levels and lower barrier levels are in favour of doing BSE. BSE performance was directly associated with higher scores of confidence, motivation and confidence to perform BSE, and indirectly associated with barriers to perform BSE. However, after adjusting for sociodemographic characteristics, family history of $\mathrm{BC}$ and total knowledge score of $\mathrm{BC}$, barriers and confidence domains of HBM were the significant predictors of BSE performance. Other significant predictors of BSE performance were higher scores of the overall knowledge on $\mathrm{BC}$, employment status and positive family history of $\mathrm{BC}$. These findings were in agreement with the results of previous studies [21-23], and could reflect the validity of use of the HBM in prediction of BSE performance among Saudi females.

The findings of the present study indicate that women with higher levels of BSE confidence have lower risks for not doing BSE. This was in agreement with previous studies [50]. Furthermore, women having lower levels of BSE barriers have higher potential for doing BSE. Results of previous research; barriers, health motivation, BSE benefits, and susceptibility are all related to BSE behavior $[51,52]$. These results complied with the structure of HBM. On the basis of HBM theory, high perceptions of

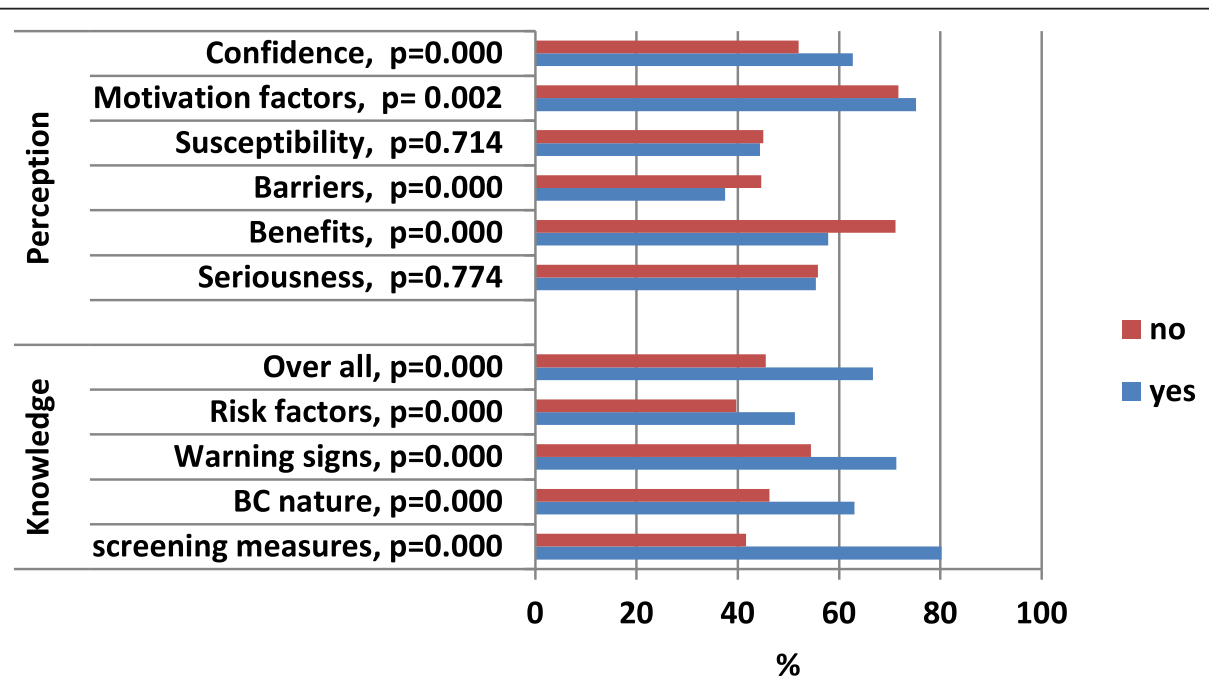

Fig. 3 Relationship between BSE performance (Yes \& no) and percentage mean scores of knowledge and attitude scales 
Table $\mathbf{5}$ Logistic regression analysis of BSE performance with some independent variables

\begin{tabular}{llllll}
\hline Independent predictors & $B$ & S.E. & p-value & OR & $95 \%$ C.I \\
\hline Age group & -.231 & .305 & .448 & .794 & $.437: 1.442$ \\
Educational status & 1.549 & .908 & .088 & 4.707 & $.794: 27.894$ \\
Marital status & .441 & .273 & .106 & 1.554 & $.910: 2.654$ \\
Monthly income & -.110 & .262 & .675 & .896 & $.536: 1.497$ \\
Knowledge score & .054 & .008 &.$<0.001^{\mathrm{a}}$ & 1.055 & $1.039: 1.072$ \\
Seriousness score & .013 & .010 & .186 & 1.014 & $.994: 1.034$ \\
Benefits score & .010 & .010 & .352 & 1.010 & $.989: 1.030$ \\
Barriers score & -.025 & .012 & $.046^{\mathrm{a}}$ & .976 & $.952: 1.000$ \\
Susceptibility score & .010 & .008 & .208 & 1.011 & $.994: 1.027$ \\
Motivation score & .001 & .012 & .920 & 1.001 & $.978: 1.024$ \\
Confidence score & .032 & .009 & $.001^{\mathrm{a}}$ & 1.032 & $1.013: 1.052$ \\
BC Family history & .744 & .292 & $.011^{\mathrm{a}}$ & 2.104 & $1.188: 3.726$ \\
Employment status & .561 & .261 & $.032^{\mathrm{a}}$ & 1.752 & $1.051: 2.921$ \\
Constant & -8.251 & 1.732 & $<.001$ & $<.001$ & \\
\hline
\end{tabular}

Cl Confidence intervals

${ }^{\text {a }}$ Statistically significant

health motivation, BSE benefits, BSE self-efficacy and low perceptions of barrier and perceived susceptibility to breast cancer demonstrate increased levels of BSE status [18, 53, 54].

The socio-demographic characteristics of individuals can directly influence their attitude and indirectly affect healthrelated behavior [51]. Previous researches revealed that the health motivation of the participants who were well educated is quite high than who were not [48, 55-57]. In the present study, after adjustment for other potential confounders, education level was not a significant predictor of BSE performance. This was in agreement with previous studies [28], however it was not in agreement with the results of other studies that emphasized the relationship between the women's educational status and BSE performance $[18,58]$. In our study, the majority of women were educated, with only a few of them who were non-educated. The role of age in the frequency of BSE practice is controversial, while some study showed a negative association between age and BSE; others reported a positive association [28]. However, in the present study, age was not a significant predictor of BSE practice. This was also the situation for marital status, and monthly income.

It has been reported that the multi-responsibilities of working women, and shortage of time urge the working women to postpone their own affairs for the sake of other family members [27]. However, in the present study, employment was the only significant socio-demographic predictor of BSE practice, and working women were more likely to perform BSE Working women are more exposed to the different sources of information about $\mathrm{BC}$ and more likely to be enrolled in educational campaigns that were shown as the main source of information in the present study.

Adequate accumulation of knowledge on breast cancer has a positive effect on BSE practice $[59,60]$. A significant number of women present with advanced stages of the disease due to lack of information, knowledge and awareness of early detection measures [28]. In the present study, lower levels of knowledge on BSE in particular and on BC in general were detected. The overall level of knowledge on $\mathrm{BC}$ was low. Less than one-half of all women reported correct information about the timing or frequency of BSE performance. Knowledge of screening measures was also low. All domains of knowledge on $\mathrm{BC}$ were significantly associated with BSE performance. Meanwhile, the overall knowledge score was a significant predictor of BSE performance. This was in agreement with the results of other previous studies [61-63]. It has been reported that increased breast awareness may have contributed in the decrease in mortality from breast cancer in some countries, although uncertainty exists whether the benefits of BA outweigh the harms [16]. Thus, involvement of the women in the community to participate in the development and implementation of health education programs on breast awareness is a necessity [61].

Madanat and Merrill [64] have reported that women with a history of breast cancer in the family have more general information on breast cancer and awareness of breast cancer screening tests than other women. Studies have also reported that women with a history of breast cancer in the family perform BSE more regularly [58, 65]. This was in agreement with the present study where family history of $\mathrm{BC}$ was a significant predictor of BSE performance. The reason may be that they know the relationship between genetic factors and breast cancer, so they see themselves as possessing such risk factors. One of the reasons preventing women from performing screening methods such as BSE regularly was the fear of finding a mass during the examination and the fear of surgery $[5,66,67]$.

This study has some limitations. First, because the study was cross-sectional, a temporal relationship between exposure and outcome cannot be established. It is clear that the true causal relationships among all of the identified variables are complex and often reciprocal. For example, knowledge and attitude of the women on BSE may be affected by many confounders other than those used in the present study. Second, the small number of. Second, it was conducted in one center, and women who participated in the study may not be representative of the whole female population in Saudi Arabia, and this would affect the generalizability of the results. Another limitation is that the data collection was based on a self administered questionnaire, thus data might have been subjected to information bias (recall bias). 


\section{Conclusion}

In the present study, women had poor knowledge on breast cancer, reported negative attitude towards BSE and their practice was poor. Reasons for not doing BSE as reported not knowing how to examine their breast was the main reason for poor practice. Women with higher perception of BSE confidence have lower risks for not doing BSE, and women having lower levels of BSE barriers have higher potential for doing BSE. Employment was the only significant socio-demographic predictor of BSE practice. The role of health providers was limited, reflecting the need to improve awareness programs by health care professionals. These findings suggest that there is a need for continuing education programs to upgrade knowledge, change attitude, confidence and behavior towards BSE. Emphasis should be laid on BSE in undergraduate and postgraduate courses. It is important to establish specialized resource centers in different regions in Saudi Arabia, to promote and integrate BSE training programs for all working women. Periodic follow up of female employees and other women in different settings in the community is very important to ensure early detection of cases. Meanwhile, BSE training programs must be adopted as one of the routine services offered to the working females. Health professionals should advise women to be "breast aware" and inform them what changes may indicate cancer and how to seek appropriate advice.

\section{Abbreviations}

BC: Breast cancer; BSE: Breast self examination; HBM: Health Belief Model; CHBMS: Champion's Health Belief Model Scale; CAM: Cancer Awareness Measure; PMS: Percentage mean score; CBE: Clinical breast examination; BA: Breast awareness; KAMC: King Abdulaziz Medical City; HRT: Hormone replacement therapy; OCP: Oral contraceptive pills; KAIMRC: King Abdullah International Medical Research Center.

\section{Competing interests}

The authors report no conflicts of interest in this work.

\section{Authors' contributions}

MAA conceived of the study, performed the statistical analysis and wrote the final draft, ASA participated in its design and coordination and helped to draft the manuscript, $A A B \& A A M \& M H A \& A F A$ participated in the design of the study, data collection, data entry, cleaning the data and statistical analysis, and helped to draft and revise the manuscript. All authors read and approved the final manuscript.

\section{Acknowledgments \\ This study was initiated and funded by the King Abdullah International Medical Research Center (KAIMRC). This work was presented at the 6th Research Summer School program of KAIMRC in July 2014.}

\footnotetext{
Author details

${ }^{1}$ King Abdullah International Medical Research Center (KAIMRC), Mail Code 1515, Riyadh, Saudi Arabia. ${ }^{2}$ King Saud bin-Abdulaziz University for Health Sciences (KSAU-HS), Riyadh, Saudi Arabia. ${ }^{3}$ King Abdulaziz Medical City, Ministry of National Guard - Health Affairs, POB 22490, Riyadh 11426, Saudi Arabia.
}

Received: 23 June 2015 Accepted: 17 November 2015

Published online: 23 November 2015

\section{References}

1. Saudi Cancer Registry. Cancer incidence reports [Internet]. Saudi Arabia: Saudi Cancer Registry; 2008 p. 36. Available from: http://www.chs.gov.sa/Ar/ HealthRecords/CancerRegistry/CancerRegistryReports/ Incidence\%20Report\%202008.pdf

2. Elkum N, Dermime S, Ajarim D, Al-Zahrani A, Alsayed A, Tulbah A, et al. Being 40 or younger is an independent risk factor for relapse in operable breast cancer patients: the Saudi Arabia experience. BMC Cancer. 2007;7(1):222.

3. Alsaif AA. Breast self-examination among Saudi female nursing students in Saudi Arabia. Saudi Med J. 2004:25(11):1574-8.

4. Radi SM. Breast cancer awareness among Saudi females in Jeddah. Asian Pac J Cancer Prev. 2013;14(7):4307-12.

5. Ceber E, Soyer MT, Ciceklioglu M, Cimat S. Breast cancer risk assessment and risk perception on nurses and midwives in Bornova Health District in Turkey. Cancer Nurs. 2006;29(3):244-9.

6. Othman A, Ahram M, Al-Tarawneh MR, Shahrouri M. Knowledge, Attitudes and Practices of Breast Cancer Screening Among Women in Jordan. Health Care Women Int. 2015;36(5):578-92.

7. Arevian M, Noureddine S, Abboud S. Beliefs related to breast cancer and breast cancer screening among Lebanese Armenian Women. Health Care Women Int. 2011;32(11):972-89.

8. Mahfouz AA, Hassanein MH, Nahar S, Farheen A, Gaballah II, Mohamed A, et al. Breast cancer knowledge and related behaviors among women in Abha city, southwestern Saudi Arabia. J Cancer Educ. 2013;28(3):516-20.

9. El Bcheraoui C, Basulaiman M, Wilson S, Daoud F, Tuffaha M, AlMazroa MA, et al. Breast Cancer Screening in Saudi Arabia: Free but Almost No Takers. PLoS One. 2015;10(3):e0119051.

10. Thomas DB, Gao DL, Ray RM, Wang WW, Allison CJ, Chen FL, et al. Randomized trial of breast self-examination in Shanghai: final results. J Natl Cancer Inst. 2002;94(19):1445-57.

11. Semiglazov V, Manikhas A, Moiseenko V, Protsenko S, Kharikova R, Seleznev I, et al. Results of a prospective randomized investigation [Russia (St. Petersburg)/WHO] to evaluate the significance of selfexamination for the early detection of breast cancer. Vopr Onkologii. 2002;49(4):434-41

12. Kosters J, Gotzsche P. Regular self-examination or clinical examination for early detection of breast cancer. Int J Epidemiol. 2008;37(6):1219.

13. U.S. Preventive Services Task Force. Screening for Breast Cancer. Summary of Recommendations. Nov. 2009. www.uspreventiveservicetaskforce.org

14. Allen TL, Van Groningen BJ, Barksdale DJ, McCarthy R. The breast selfexamination controversy: what providers and patients should know. J Nurse Pract. 2010;6(6):444-51.

15. Austoker J. Breast self examination: Does not prevent deaths due to breast cancer, but breast awareness is still important. BMJ. 2003;326(7379):1.

16. Thornton H, Pillarisetti RR. 'Breast awareness' and 'breast self-examination' are not the same. What do these terms mean? Why are they confused? What can we do? Eur J Cancer. 2008:44(15):2118-21.

17. Dandash KF, Al-Mohaimeed A. Knowledge, attitudes, and practices surrounding breast cancer and screening in female teachers of Buraidah, Saudi Arabia. Int J Health Sci. 2007;1(1):61.

18. Petro-Nustus W, Mikhail BI. Factors Associated with Breast Self-Examination Among Jordanian Women. Public Health Nurs. 2002;19(4):263-71.

19. Canbulat N, Uzun Ö. Health beliefs and breast cancer screening behaviors among female health workers in Turkey. Eur J Oncol Nurs. 2008;12(2):148-56.

20. Mikhail BI, Petro-Nustas WI. Transcultural adaptation of Champion's health belief model scales. J Nurs Scholarsh. 2001;33(2):159-65.

21. Savage SA, Clarke VA. Factors associated with screening mammography and breast self-examination intentions. Health Educ Res. 1996;11(4):409-21.

22. Yarbrough SS, Braden CJ. Utility of health belief model as a guide for explaining or predicting breast cancer screening behaviours. J Adv Nurs. 2001;33(5):677-88.

23. Champion V, Menon U. Predicting mammography and breast selfexamination in African American women. Cancer Nurs. 1997;20(5):315-22.

24. Secginli S, Nahcivan NO. Factors associated with breast cancer screening behaviours in a sample of Turkish women: a questionnaire survey. Int J Nurs Stud. 2006:43(2):161-71.

25. Alam AA. Knowledge of breast cancer and its risk and protective factors among women in Riyadh. Ann Saudi Med. 2006;26(4):272.

26. Amin T, Al Mulhim A, Al MA. Breast cancer knowledge, risk factors and screening among adult Saudi women in a primary health care setting. Asian Pac J Cancer Prev. 2009;10(1):133-8. 
27. Sharaa HM. Beliefs and Reported Practices Related to Breast Self Examination among Sample of Egyptian Women. 2013.

28. Agboola A, Deji-Agboola A, Oritogun K, Musa A, Oyebadejo T, Ayoade B. Knowledge, Attitude and Practice of Breast Self Examination in Female Health Workers in Olabisi Onabanjo University Teaching Hospital, Sagamu, Nigeria. The International Medical Journal. 2009;8(1):5-10.

29. Alwan N, Al Attar W, Eliessa R, Madfaic Z, Tawfeeq F. Knowledge, attitude and practice regarding breast cancer and breast self-examination among a sample of the educated population in Iraq. 2012.

30. Breast Module of the Cancer Awareness Measure (Breast-CAM) . 2nd ed. Cancer Research UK, King's College London and University College London; 2009. Available from: http://www.cancerresearchuk.org/prod_consump/ groups/cr_common/@nre/@hea/documents/generalcontent/cr_046977.pdf

31. Champion VL. Instrument refinement for breast cancer screening behaviors. Nurs Res. 1993:42(3):139-43.

32. Balogun $M$, Owoaje E. Knowledge and practice of breast self-examination among female traders in Ibadan Nigeria. Annals Ibadan Postgraduate Med. 2007;3(2):52-6.

33. Ahmed BA. Awareness and practice of breast cancer and breast-self examination among university students in Yemen. Asian Pac J Cancer Prev. 2009;11(1):101-5.

34. Obaikol R, Galukande M, Fualal J. Knowledge and Practice of Breast Self Examination among Female Students in a Sub-Saharan African University. 2010.

35. Millat W. Knowledge of secondary-school female students on breast cancer and breast self-examination in Jeddah, Saudi Arabia. 2000

36. Jahan S, Al-Saigul AM, Abdelgadir MH. Breast cancer. Knowledge, attitudes and practices of breast self examination among women in Qassim region of Saudi Arabia. Saudi Med J. 2006;27(11):1737-41.

37. Kashgari RH, Ibrahim AM. Breast cancer: Attitude, knowledge and practice of breast self examination of 157 Saudi women. J Fam Commun Med. 1996;3(1):10.

38. Persson K, Johansson I, EK AC. Breast self-examination among Swedish women: A survey of frequency, knowledge, and attitudes. J Cancer Educ. 1995;10(3):163-7.

39. Janda M, Obermair A, Haidinger G, Waldhoer T, Vutuc C. Austrian women's attitudes toward and knowledge of breast self-examination. J Cancer Educ 2000;15(2):91-4

40. Salaudeen A, Akande T, Musa O. Knowledge and attitudes to breast cancer and breast self examination among female undergraduates in a state in Nigeria. Eur J Soc Sci. 2009;7(3):157-65.

41. Abdel FM. Breast self-examination practice and its impact on breast cancer diagnosis in Alexandria, Egypt. 2000.

42. Wardle J, Steptoe A, Smith H, Groll-Knapp E, Koller M, Smith D, et al. Breast self-examination: attitudes and practices among young women in Europe. Eur J Cancer Prev. 1995:4(1):61-8.

43. $\mathrm{Ng} \mathrm{K}$, Fung $\mathrm{S}$, Chow L. Practice of breast self-examination among high risk Chinese women in Hong Kong. Chin Med J (Engl). 2000;113(12):1100-3.

44. Pavia M, Ricciardi G, Bianco A, Pantisano P, Langiano E, Angelillo IF. Breast and cervical cancer screening: Knowledge, attitudes and behaviour among schoolteachers in Italy. Eur J Epidemiol. 1999;15(4):307-11.

45. Odusanya O. Breast cancer: knowledge, attitudes, and practices of female schoolteachers in Lagos, Nigeria. Breast J. 2001;7(3):171-5.

46. Parsa P, Kandiah M, Mohd Zulkefli NA, Rahman HA. Knowledge and behavior regarding breast cancer screening among female teachers in Selangor Malaysia. Asian Pac J Cancer Prev. 2008;9(2):221-7.

47. Haji-Mahmoodi M, Montazeri A, Jarvandi S, Ebrahimi M, Haghighat S, Harirchi I. Breast Self-Examination: Knowledge, Attitudes, and Practices Among Female Health Care Workers in Tehran, Iran. Breast J. 2002;8(4):222-5.

48. Nahcivan NO, Secginli S. Health beliefs related to breast self-examination in a sample of Turkish women. Oncol Nurs Forum. 2007:34(2):425-32.

49. Gaballah I. Awareness, Knowledge and Practice of Breast Self-Examination Among Saudi Women. Med. J. Cairo Univ. 2011;79(2):81-6.

50. Tastan S, lyigün E, Kilıc A, Unver V. Health beliefs concerning breast selfexamination of nurses in Turkey. Asian Nursing Res. 2011;5(3):151-6.

51. Champion VL, Miller TK. Variables related to breast self-examination: Model generation. Psychol Women Quart. 1992;16(1):81-96.

52. Tavafian SS, Hasani L, Aghamolaei T, Zare S, Gregory D. Prediction of breast self-examination in a sample of Iranian women: an application of the Health Belief Model. BMC Women's Health. 2009;9(1):37.

53. Champion VL, Scott CR. Reliability and validity of breast cancer screening belief scales in African American women. Nurs Res. 1997;46(6):331-7.
54. Gözüm S, Aydin I. Validation evidence for Turkish adaptation of Champion's Health Belief Model scales. Cancer Nurs. 2004;27(6):491-8.

55. Yavari P, Pourhoseingholi MA. Socioeconomic factors association with knowledge and practice of breast self-examination among Iranian women. Asian Pac J Cancer Prev. 2007;8(4):618-22.

56. Kara B, Acikel $\mathrm{CH}$. Health beliefs and breast self-examination in a sample of Turkish nursing students and their mothers. J Clin Nurs. 2009;18(10):1412-21.

57. Avcl IA. The health beliefs relating to mammography of midwives and nurses. Meme Sağlığı Dergisi. 2007;3(2):4-9.

58. Karayurt O, Dramal A. Adaptation of Champion's Health Belief Model Scale for Turkish women and evaluation of the selected variables associated with breast self-examination. Cancer Nurs. 2007;30(1):69-77.

59. Dündar PE, Özmen D, Öztürk B, Haspolat G, Akyıldız F, Çoban S, et al. The knowledge and attitudes of breast self-examination and mammography in a group of women in a rural area in western Turkey. BMC Cancer. 2006;6(1):43.

60. Okobia MN, Bunker CH, Okonofua FE, Osime U. Knowledge, attitude and practice of Nigerian women towards breast cancer: a cross-sectional study. World J Surg Oncol. 2006;4(1):11.

61. Jumah JAB. Knowledge \& Practice of Saudi Women about the Prevention of Breast Cancer. International Journal of Applied. 2013;3(2):8-13.

62. Grunfeld E, Ramirez A, Hunter M, Richards M. Women's knowledge and beliefs regarding breast cancer. Br J Cancer. 2002;86(9):1373-8.

63. McMenamin M, Barry H, Lennon A-M, Purcell H, Baum M, Keegan D, et al. A survey of breast cancer awareness and knowledge in a Western population: lots of light but little illumination. Eur J Cancer. 2005;41(3):393-7.

64. Madanat $\mathrm{H}$, Merrill RM. Breast cancer risk-factor and screening awareness among women nurses and teachers in Amman Jordan. Cancer Nurs. 2002; 25(4):276-82.

65. Cavdar Y, Akyolcu N, Ozbaş A, Oztekin D, Ayoğu T, Akyüz N. Determining female physicians' and nurses' practices and attitudes toward breast selfexamination in Istanbul, Turkey. Oncol Nurs Forum. 2007;34(6):1218-21.

66. Demirkiran F, Balkaya NA, Memis S, Turk G, Ozvurmaz S, Tuncyurek P. How do nurses and teachers perform breast self-examination: are they reliable sources of information? BMC Public Health. 2007;7(1):96.

67. Dirksen S, Lewis S. Nursing Management: Breast Disorders. Medical-surgical nursing: Assessment and Management of Clinical Problems (SM Lewis, MM Heitkemper, SR Dirksen, eds). 2004:1360-83.

\section{Submit your next manuscript to BioMed Central and we will help you at every step:}

- We accept pre-submission inquiries

- Our selector tool helps you to find the most relevant journal

- We provide round the clock customer support

- Convenient online submission

- Thorough peer review

- Inclusion in PubMed and all major indexing services

- Maximum visibility for your research

Submit your manuscript at www.biomedcentral.com/submit 